\title{
A Case Study of a 15-Minute City Concept in Singapore's 2040 Land Transport Master Plan: 20-Minute Towns and a 45-Minute City
}

\author{
Odilia Renaningtyas Manifesty ${ }^{1^{*}}$, Jin Young Park² \\ ${ }^{1}$ Urban Planning and Design Lab, Department of Architecture, College of Engineering, Korea University, Seoul, \\ South Korea \\ ${ }^{2}$ Global Urban Development Office, Seoul Housing and Communities Corporation, South Korea \\ *Email: ormreyn@korea.ac.kr
}

\begin{abstract}
The 15-Minute city concept emerged as a response to the hyper-motorized city. First popularized by the Mayor of Paris in 2020, 15-Minute City is an evolving concept that derived from its predecessors such as neighborhood-unit planning and walkable city. This paper explores the implementation of the 15-Minute City concept in city planning by using Singapore as the case study. In 2018, Singapore released its Land Transport Master Plan 2040 and which includes an ambitious concept of 20-Minute Towns and a 45-Minute City (2MT45MC) and has similar ideas to the 15-Minute City concept. Through various journal articles and media coverage, Singapore's policy and regulation regarding its transport planning were thoroughly reviewed to find Singapore's strategy and challenges in realizing the objective of its $2 \mathrm{MT} 45 \mathrm{MC}$ concept. Normalizing active mobility and enhancing connectivity nationwide are the main strategies to overcome the biggest challenges faced: lack of legal backing in personal mobility devices and the country's rigid zoning. Even though it is too early to say whether $2 \mathrm{MT} 45 \mathrm{MC}$ is achievable or not, projects such as the North-South Corridor show that for a long-term plan, it seems feasible.
\end{abstract}

\section{Keywords}

15-minute city; Singapore's land transport planning; Sustainable transport planning; Active mobility

\section{Introduction}

After modernism made cars and other motorized vehicles the center of city planning in the early 1930s [1], cities started to redefine their space to be more humanist. Movements and critiques against the mechanization of the city started to rise, and slowly, the design and planning paradigms changed into more people-centered strategies [2]. The new paradigms emphasize how to create a city where humans do not have to depend on cars to reach their destination. Here is when the 15-Minute city came to the discussion, as the culmination of earlier paradigms opposing the modern movement in urban and transportation planning. In contrast to railway or highway projects that use motorized vehicles to connect people to the city center, 15-Minute City brings the destinations closer to the users by creating a poly-centric city [3]. Adapted by many countries with their own adjustments (some countries use 20-Minute City, some others use a concept of Complete Streets), 15-Minute City got more popular when the Covid19 pandemic hit the world, and people's movement is getting limited. Singapore is one of the major cities that, with the release of their newest 2040 master plan, is introducing their own version of 15Minute City: 20-Minute Towns and a 45-Minute City.
This paper explores the development of the 15-Minute City concept and Singapore's effort to implement it, as shown in their 2040 land and transport system. This paper presents an overview of Singapore's transport planning that, to the authors believe, is in accordance with the concept of a 15-Minutes City as stated in its latest Land and Transport Master Plan. The topic is presented in this paper through three main parts: an overview of the 15-Minute City concept, a review of Singapore's policy and regulation regarding its transport planning, and how the 15-Minute City concept is reflected on Singapore's current land and transport planning. Besides Introduction and Methodology, this paper consists of five other sections that include the main body and a reflection. In section 3 , we present the definition, background, and principles of a 15-Minute City. In the next section, we started our introduction of Singapore's transportation planning strategies and how their infrastructure is able to support the strategies. The strategies are explained further in section 5 with emphasis on active mobility, the main transportation mode that is promoted by the 15-Minute City concept [4]. The goal of achieving more active mobility was used as one of the bases of Singapore's newest transportation plan that is presented thoroughly in 
section 6. The last section will present perspective and reflection on how far Singapore has translated the concept of 15-Minute City into their own planning strategies.

\section{Objectives and Methodology}

The purpose of this study is to (i) review the current state of 15-Minute City as a concept in urban and transportation planning, (ii) present a case study of how the 15-Minute City principles are adapted in an urban master planning, and (iii) present a perspective on how feasible the 15-Minute City concept is, based on available literature. To achieve the study's purposes, the author reviewed existing publications and mass media related to the topic in order to get an understanding of the principles of the 15-Minute City concept. The author used the Publish or Perish software to collect papers from the year 2000 to 2021 with "15-minute city" as the keyword. Google Scholar was selected as the database and 200 papers were collected. The second filtering was conducted with additional keywords that are more relatable to the research: urban planning, urban design, case study, and implementation.

Finally, a quick screening was conducted by the author to get more focused articles on how the theory is implemented in transportation and land use planning. Subsequently, an intensive study on Singapore's newest Land Transport Master Plan was conducted to find out how the nation interpreted, developed, and implemented the concept in accordance with the country's needs and characteristics. A total of 56 articles were collected and reviewed for this study. Finally, personal communication about the generalization of the topic was conducted with four colleagues residing in Singapore: two citizens and two long-term residents. All four respondents have been living in Singapore for at least five years and hence have the capability of giving inputs about the impact of the regulations related to the topic towards the residents of Singapore.

\section{$3 \quad$ 15-Minute City as a Future Key for Sustainable Urban Planning}

When cars were invented, the city planning system changed to fit the flooding number of cars on the street [5]. Urban sprawl started to form since cars allowed people to travel further. Because of that, cars have been seen to be a necessity in terms of transportation. Numerous critiques have since risen, demanding more humanist cities that put people above private cars. Future issues of urban pollution also added to the urgency of changing the direction of the development of cities. Current socio-economic and health issues such as the Covid-19 pandemic pushed the city to critically rethink its planning system. As Moreno et al. [3] have stated, 15-Minute City is one example of innovative thinking to make cities a healthier place to live.

Looking at the history of urban planning and design, 15Minute City is not a completely new planning strategy, but more of a culmination and updated version of earlier paradigms such as garden city by Ebenezer Howard (1898) and neighborhood unit by Clarence Perry (1929). First popularized by the Mayor of Paris, Anne Hidalgo, 15-Minute City is getting popular worldwide because it promotes public health with active movement where people are encouraged to walk or ride their bicycles to their desired destination. The main idea of the 15-Minute city is quite simple: basic human needs in a city must be accessible by the residents within a 15minute commute from their residence [6].

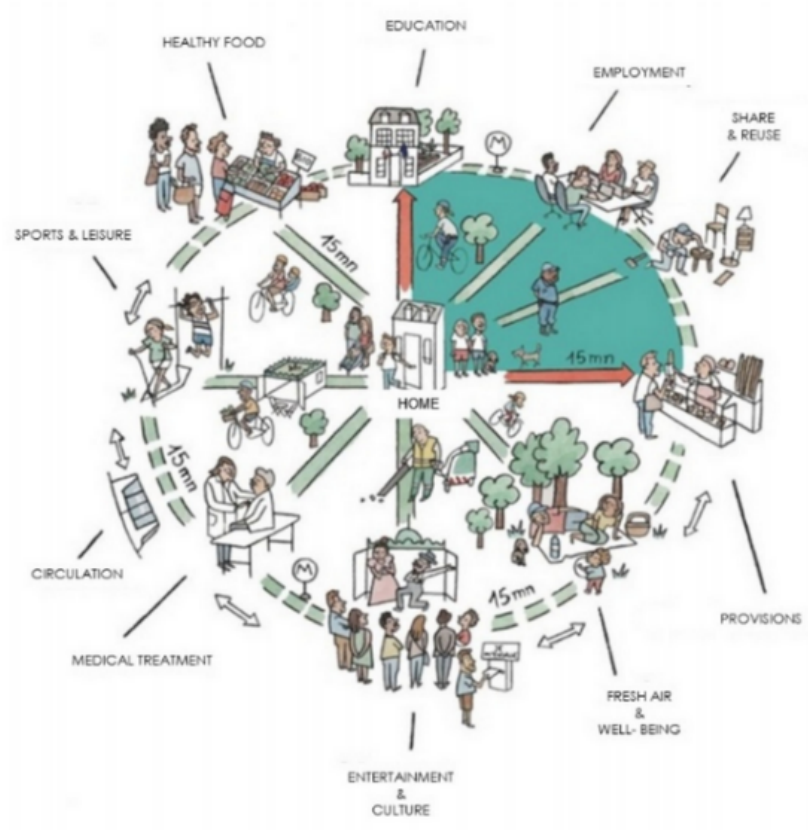

Figure 1 The 15-minute city concept. Adapted from [4].

In 15-Minute City, private cars are largely absent in the planning strategies. It is because of the impossibility of using private cars without creating much traffic, making it a transportation mode that is not environmentally friendly. Walking and cycling are the most preferred modes since it promotes a greener environment and healthier lifestyle. Public transportation was also favored during the first discussions of the concept but quickly left behind since the surge of Covid-19 pandemic in early 2020 pushed people to distance themselves from each other physically. The pandemic has made it very difficult for people to be dependent on public transport as their primary transportation mode [7]. The Work From Home policy that seems to be implemented everywhere worldwide due to the 
pandemic has made the necessity to travel decline and the usage of long-distance travel mode become less and less, especially in the congested urban areas [8]. In the era where cities are demanded to enhance their health protocol to the highest while keeping their economic activities high, the usage of public transport has been declining worldwide [9]. According to the coalition of 97 countries dedicated to creating more sustainable cities called C40, there are four cores in 15-Minute City planning: easy access to goods and services, variety of housing types, access to clean and fresh air, and the presence of smaller-scale offices. The C40 also suggested that with a disruption in the scale of the Covid-19 Pandemic, there has never been a better time to rethink the proximity and completeness of a neighborhood.

This idea has also been the reason that pushed Anne Hidalgo, the mayor of Paris, to make 15-Minute City one of her core strategies in the 2020 election [10]. Paris' plan of a polycentric city is also a strategy to tackle the global pandemic that started in early 2020. Most countries are struggling to contain the infection rate because their cities are applying concentrated planning where people go to work in the same area. This type of planning could make the city center overcrowded and makes it easy for the infection to spread. Paris planned to use the 15-Minute City concept to slow down the infection by dispersing the city center. Even before the Pandemic, 15-Minute City was proposed to promote a healthier community and greener environment [11]. With every facility placed near the houses, as shown in Figure 1, the need to use motorized vehicles decreased, and people were encouraged to walk more. Not only walking, but this concept should also be able to encourage any form of active mobility that will be investigated further in the next chapter of this paper.

Implementing the 15-Minute City concept to urban planning policies can be a rigorous process. To translate the concept into urban policies and regulations, tangible elements that make a city 15-Minute City should be measured. Carmona proposed four core elements to describe what makes a 15-Minute City. Transportation, density, diversity, and proximity are the tangible qualities of the concept [12]. Since those elements are tangible and measurable, policies aimed to transform a city with a 15-Minute City concept should pay attention to the four elements and translate them into various regulations. The biggest challenge of the concept is providing the necessary infrastructure. Safe, comfortable, and separated pedestrian paths and bicycle lanes are needed to support the concept. Paris has leveled up the concept and turned it into a more artistic urban concept. The city has moved on from rigid distinct city zoning to the 'mosaics neighborhoods' concept where mixed-use neighborhood units formed a polycentric city. In the near future, the implemented 15Minute City concept is predicted to be the key to creating stronger local communities and rediscovering locality that can lead to the improvement of the life quality of the residents [13].

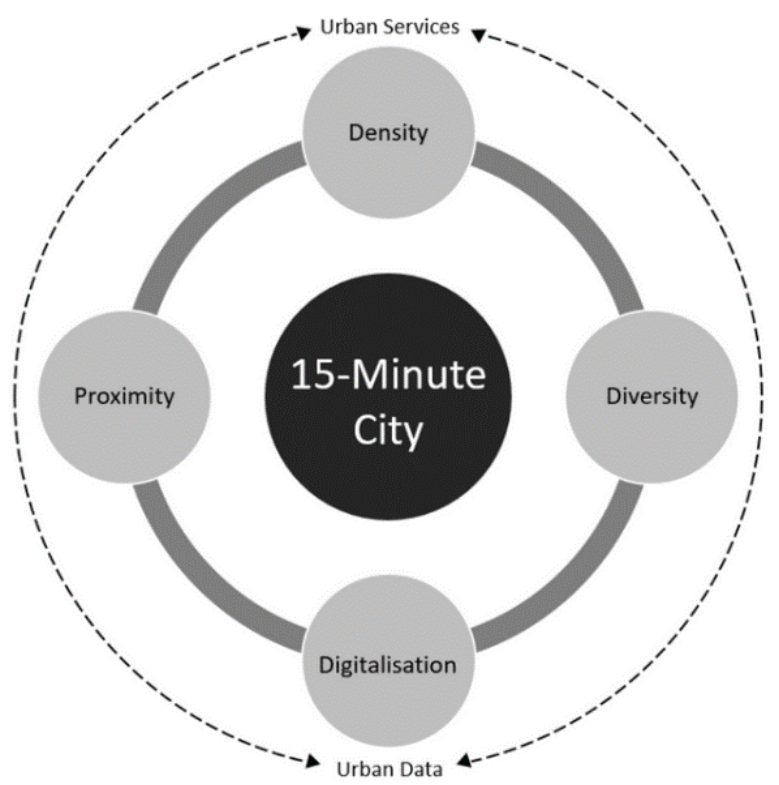

Figure 2 The 15-minute city framework. Adapted from [3].

Since the concept requires major urban facilities to be placed in close proximity to the residential areas, six essential urban functions (living, working, commerce, healthcare, education, and entertainment) need to be contained within the 15-minute radius of a neighborhood. Among the functions, business (where most people work) is the most challenging function to be put closer to the residential facility. The century-long segregation between the jobs and the houses has led to people's severe dependency on automobiles and it is the total opposite of what the 15-Minute City concept believes [14]. The end of the Second World War promoted even further decentralization of the industrial and office zone where they were put in a large-scale planning district in a remote area and gathered its employees from dispersed regions [15]. However, in modern society, home and jobs are required to have a reciprocal relationship since what happens at home affects people's behavior at work and vice versa [16]. Jobs are also no longer related only to the adult males of the house, but teenagers and students need access to the work environment too for academic and training purposes. The number of women joining the workforce is also increasing every year. Proximity became critical 
here to integrate jobs into daily household life. With the Covid-19 pandemic phenomenon, it has been proven that working from home is actually possible for many kinds of jobs.

To integrate the six essential urban functions into the city, Paris created a feasible planning network, as shown by Figure 2. The plan consists of four dimensions: density, diversity, digitalization, and proximity to help implement the concept. Optimal density will help the 15-Minute city be socially sustainable by putting an optimal number of people in a neighborhood [17]. However, careful consideration regarding the urban density is needed to provide enough open space for urban air corridors. The concept of proximity is to bring human scale to the city so that timewise, the city is highly accessible by the people without the help of motorized vehicles. Diversity would probably be the main key in the framework and it needs to be viewed in a detailed manner, such as the building's usage, as well as social and cultural diversity [18]. Digitalization is a means to make everything faster by combining digital literacy to people's movement, for example, the bike-sharing system that allows people who do not have a bicycle to rent it in a matter of seconds. The main purpose of digitalization is to give people easy access to healthier transportation modes by utilizing the concept of the Internet of Things, where devices and smart technologies are connected, at an urban level.

\section{$4 \quad$ Land and Transport Planning in Singapore: the "Avoid - Shift - Improve" Paradigm}

In 2021, Singapore continues to top various rankings related to a city's well-being. This includes being number 11 th on the world's best cities by Schroders, the first on the list of the world's smartest cities, and also number one in Covid Resilience Ranking by Bloomberg [19]-[21]. All these accomplishments have made Singapore often regarded as one of the best examples of city management. However, gaining independence only in 1965, things have not always been easy for Singapore to develop and maintain. With a growing 5.5 million population, 14 percent of their already limited land has gone to housing and 12 percent of it went to the road system [22]. The current condition of Singapore's road infrastructure has successfully connected every part of the country. The whole island is integrated and covered by a top-tier road system making it very comfortable to travel by car. However, at some point, it would not be a wise idea to keep building and expanding the road system that will consume more land and make the development not be environmentally friendly. Not only roads, but the country's also very limited land does not allow the building of more private transport facilities, such as parking space. To overcome the issue, since the 1980 s, Singapore has put public transport as its core in transport system development [23]. For Singapore, the integration of the public transport system is not only about moving people from one point to another point but also about enhancing urban livability [24]. Based on annual data by the Ministry of National Development, the rail density in Singapore has significantly increased from $34 \mathrm{~km} /$ million population in 2012 to an expected $54 \mathrm{~km} /$ million people in 2030 . With this high density, the rail system is penetrating deep into the residential areas all around Singapore for easy access. Sheltered walkways, noise barriers, and barrier-free accessibility were installed to avoid compromising the comfort in residential areas.

Singapore's public transport system mainly consists of a highly integrated bus and subway system that covers every inch of the country. Since 1987, Singapore hasn't stopped expanding its lines for the Mass Rapid Transit system, with the sixth line finished this year and the existing plan is expected to finish in 2029 [25]. For the bus transportation system, with the Bus Service Enhancement Programme launched in 2017, the goal is to enhance reliability and connectivity by adding the number of the bus running on the streets and providing shorter routes within the communities. Looking at some of the efforts done by the government, affordability, comfort, and reliability are the keys to public transport's high popularity among the citizens. From personal experience and based on the personal communication with the respondents, Singapore's buses are really comfortable and it makes the trips enjoyable, unlike in many other countries. The seats are comfortable and the shock absorbance system is good so that people can stand inside a moving bus without hanging tight to the hand-holders.

Besides the comfort of the city buses, the backbone of public transport is still the subway (referred to as MRT, Mass Rapid Transport, in Singapore) since it can carry an optimum number of passengers in a relatively shorter time. To maintain the quality of the subway system, Singapore currently has two operators that keep competing and benchmarking to give what's best for the passengers. According to Singapore's Land and Transport Authority, both operators, SMRT and SBS Transit, positively compete to provide a better subway experience for the citizens. Research by Rahman and Chin [26], who reviewed Singapore's public land transport system in a holistic way, stated that the system is excellent in 9 key areas, including a world-class infrastructure system in which management of road-rail network and maintenance of the quality of the vehicle 
are the major efforts. Due to the aforementioned effort, Singapore's success in transport planning is comparable to other megacities in the world, such as Tokyo, Chicago, and New York and remains a role model for other metropolitan cities. Figure 3 shows that Singapore has a relatively high number of bus fleets per million passengers and a number of situations per square kilometer.

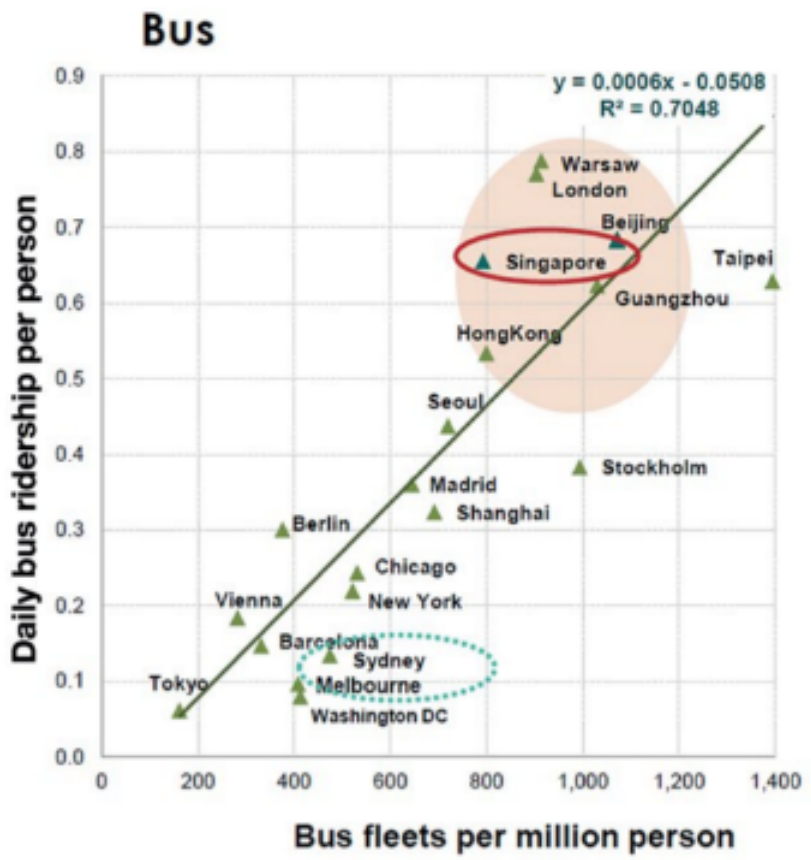

(a)

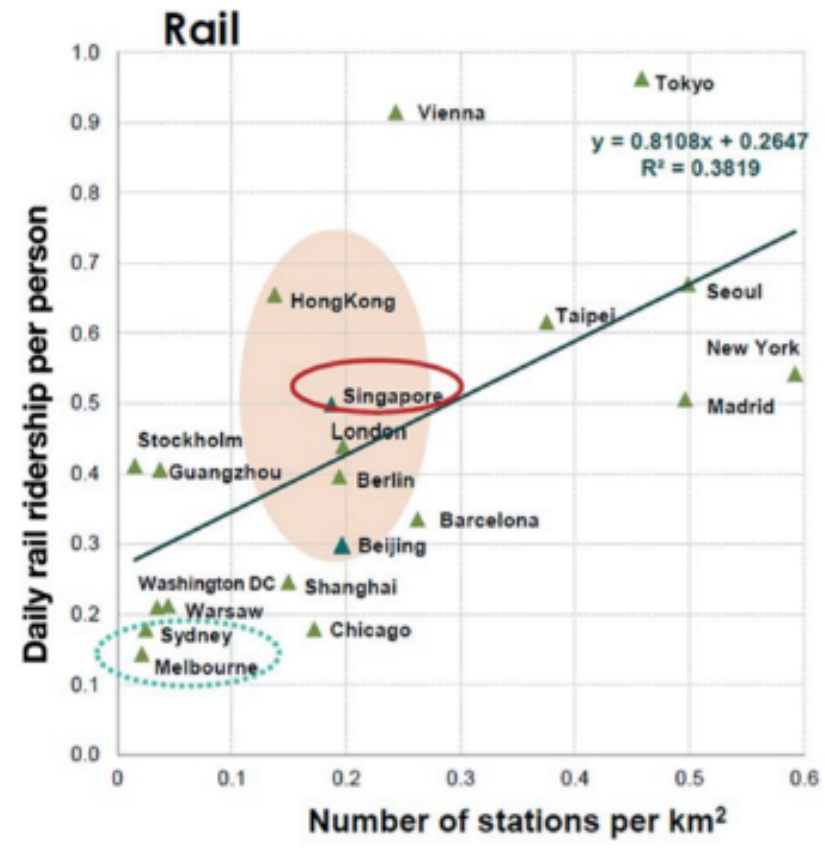

(b)

Figure 3 Public (a) bus and (b) rail usage. Adapted from [27].

In transport planning, Singapore's main strategy is to avoid - shift - improve [28]. This strategy has been strongly reflected in the country's 2040 Land Transport Master Plan. The strategy originally came from the ASIF framework by Lee Schipper, a framework consisting of four components (avoid, shift, improve, and finance) that might affect the carbon emission from transportation activities [29]. The design of the framework was motivated by the fact that the transport sector in a city is the biggest contribution to carbon dioxide emission globally. ASIF framework's original goal is to set some guidelines to push forward a more devised policy to reduce the rate of emission. The first move of the strategy, Avoid, involves cutting short the traveling distance by introducing compact development in urban areas. It means that Singapore's transport planning tries to avoid long-distance travel by bringing as many urban facilities as possible to the people so that residents do not have to travel too far to get their basic needs met. Furthermore, there is a scheme involving private vehicle ownership in Singapore that indirectly forces people to not prefer private vehicles over public transportation. Along with Hong Kong, Singapore holds the highest cost for annual vehicle ownership in Asia [30]. The annual registration fee in Singapore is the biggest in Asia and can go up to 4,000 Singapore dollars per year. Not only a high price of the annual registration fee but also owning a car in Singapore requires the owner to first bid for a permit called the Certificate of Entitlement. This certificate involves a rather complicated process and can only be given out every once in 6 months. Not to mention that the price that has the possibility of winning the bid could be up to 40 to 50 thousand Singapore dollars for a regular sedan [31]. To get a driving permit, an individual has to take a driving class that can cost up to 10,000 Singapore dollars. Based on correspondence with colleagues living in Singapore, young people in Singapore nowadays focus more on owning a house rather than a car.

All those policies and regulations are intended to reduce the use of private cars and indirectly encourage people to shift to public transportation and active mobility as the main transportation mode. This is where the Shift paradigm from the strategy comes in. Shift here means developing infrastructure that encourages people to shift away from personal vehicles to public transport that can carry more people without occupying too much space on the street. Promoting healthier urban lifestyles by encouraging people to shift to active mobility such as walking and cycling is also the goal of the shifting paradigm. While owning a private car is difficult in Singapore, shifting towards a greener transportation mode has been a long journey because, by 2013, Singapore's rail was only longer compared to Bangkok in Asia [30]. Up till the 2012, especially in a more 
remote neighborhood, Singapore's public transport system relied on the bus service. However, the government never stopped expanding the rail system even until now. After the completion of the East-West line in 2017, Singapore's rail system is not only expanding the existing five lines but also creating a new line called Thomson - East Coast line in 2021 [32].

The expansion effort of subway lines is accompanied by some strategies to increase the amount of ridership. There are several macro and micro-level factors that can affect public transport ridership. Macro-level factors include the price of gasoline for private cars and transport fare, while individual or micro factors include public transport's comfort and the walking environment quality [33]. Applying the factors into the regulation can change the rate of ridership and Singapore took close attention to the price of gasoline and transport fare to increase the number of public transport ridership. In Asia, the daily cost of the operation of private vehicles in Singapore is the second-highest after Hong Kong [34]. Ninety percent of this cost is the gasoline price and the other costs include parking and ERP, a road management system based on taxation adopted by Singapore to prevent congestion. In contrast to its gasoline price, public transport fare in Singapore is the lowest in Asia along with Seoul. This way Singapore managed to discourage the usage of private vehicles and encourage the usage of public transport.

The last phase of the strategy is to improve, which means Singapore evaluates its plan regularly and improves the part that is seen to be a weakness. Multidimensional measurements need to be conducted so the improvement can cover traffic management, environmental control, and the comfort of the users. As one of the world-renowned smart cities, Singapore keeps advancing its IoT (Internet of Things) based technologies and applications to manage the traffic [35]. The traffic management system includes the Green Link Determining to help manage traffic in junctions outside the downtown area and Intelligent Transport Systems, which is a collection of internet-based traffic information. Under the Intelligent Transport Systems, there are three main real-time services: traffic.smart, transit.smart, and route.smart [36]. Those three services are available for the public to monitor the road situation in a real-time manner. In the future, Singapore has a plan to enhance the traffic management system that includes navigational service through multi-platforms such as radio, telephones, and message signs.

In terms of environmental control, Singapore follows the global standard of allowed vehicle emission. To achieve a more environmentally friendly city, USEPA (the United States Environmental Protection Agency) stated emission particles should be larger than 2.5 millimeters for them to exist safely in the air and not to be inhaled by humans. This regulation is commonly referred to as PM (Particulate Matter) 2.5. PM 2.5 was published to set a limitation of gases and particles to let out into the air by various sources such as industrial processes and transportation vehicles. The PM 2.5 particle was set by the USEPA because particles at this size and smaller can be dangerous for those that have chronic and acute bronchitis because this particle can easily enter the lung and cause the lung's condition to worsen. However, based on a survey conducted in 2007, many developed countries such as New York, Toronto, Copenhagen, and Singapore have not yet met this requirement [37]. Since then, Singapore has been improving its vehicular emission control by setting a stringent emission standard for all registered vehicles, including both private and public transport. All registered vehicles must meet the standard of Euro IV emission. This regulation is burdensome to most private car owners since they have to go through mandatory periodic inspections related to the emission of the cars. However, private cars that use electric cars or natural gases can benefit from green vehicles rebate where $40 \%$ of the tax on cars can be reduced [37].

\section{Moving Forward from Public Transport to Active Mobility}

After the improvement of the traffic management system and green transportation has been made, people's comfort is the next thing that should be improved for better transport planning. People's comfort can be elevated by improving both motorized and non-motorized transport. For motorized transport, Singapore keeps improving the comfort and safety of its trains and buses. The interior comfort of the train and buses is important because it's the main feature that the riders can relate to regarding comforts. A quick survey conducted by a group of students from Nanyang's Girl High School in 2014 showed that $62 \%$ of the respondents said that seats in Singapore's buses are more comfortable than MRT's seats because of its cushion where MRT's seats are just hard plastic. However, most passengers stated that the seats in MRT trains are adequate because most of them are using MRT for a shorter journey than the bus [38]. In the safety aspect, Singapore always makes efforts to improve its world-renowned maintenance system. In 2018, Singapore made a rather idiosyncratic partnership with McLaren Applied Technologies, a subsidiary of McLaren, a British luxury automotive manufacturer that also participates in Formula One, to enhance the monitoring and predictive analytics system [39]. The collaboration was highly anticipated since it could 
enhance the optimization of the maintenance mechanism based on users' experience.

Non-motorized transport in Singapore is dominated by walking and cycling. Despite the challenge of tropical climates being hot and humid year-round and making active mobility a burden for most people, Singapore never stopped its efforts in promoting non-motorized transportation as a part of its urban life. Several efforts have been conducted nationwide to improve the walking and cycling environment, such as providing covered walkways to shelter people from the weather and providing obstacle-free dedicated bike lanes. Nonetheless, significant efforts are still needed to be done since people's attitude towards the development of active mobility is still relatively negative [40]. People tend to prefer walking because it's considered safer and simpler, but even with the considerable provision of sheltered walkways, walking long distances is still less likable, mostly due to the weather. On the other hand, cycling is seen to be a more enjoyable activity and even seen as a part of today's lifestyle. However, the infrastructure for cycling seems to be not equal in all areas in Singapore, making the safety aspect compromised. Moreover, the current development of the cycling path focuses more on expanding the length of the path and not the design quality [41]. Condition on the field shows that the cycling path places the bike lane just next to the pedestrian street without any barrier. This condition often leads to conflicts between cyclists and pedestrians [40]. Conflicts regarding safety often involve both parties being disrespectful towards each other. To solve this issue, Singapore is making continuous attempts to provide satisfying infrastructure for both cyclists and pedestrians.

The challenges mentioned in the previous section did not stop Singapore from aiming to put walking and cycling as main transportation modes in the future. Nearing the release of Singapore's Land Transport Master Plan (LTMP) 2040, the core strategy of strengthening the public transport system shifted to a more ambitious plan: the promotion of active mobility [42]. There are two main backgrounds for this active mobility campaign to be implemented, despite the longrunning challenges on realizing the idea. The first is related to the issue of public health. Active mobility encourages people to actively use their bodies as a mode of transport, such as walking and cycling. It will not only be beneficial for physical health, but it also helps prevent psychological issues such as depression [43]. By promoting active mobility, the health benefit does not stop only at the people actively doing it but also at the environment. When more people decide to shift into active mobility, carbon emission that comes out of motorized vehicles will also be reduced. However, as active mobility contributes to a healthier environment, without proper infrastructure, it can negatively affect the health of the people who prefer active mobility. Traffic accidents due to improper path segregation and air pollution from motorized vehicles can be harmful to cyclists and pedestrians. To avoid this backfired strategy, the planning of active mobility in urban areas should involve multi-level planning and design strategies: policies and regulation; city and region; and at neighborhood-level [44]. The government plays an important role in constructing various strategies and implementing them in the built environment of a smaller scale, the neighborhood. Within the neighborhood scale, the social approach needs to be considered because, at this level, the policies and physical design must relate to the communities and even the individuals. Promoting active mobility as a lifestyle can significantly contribute to the successful campaign of active mobility.

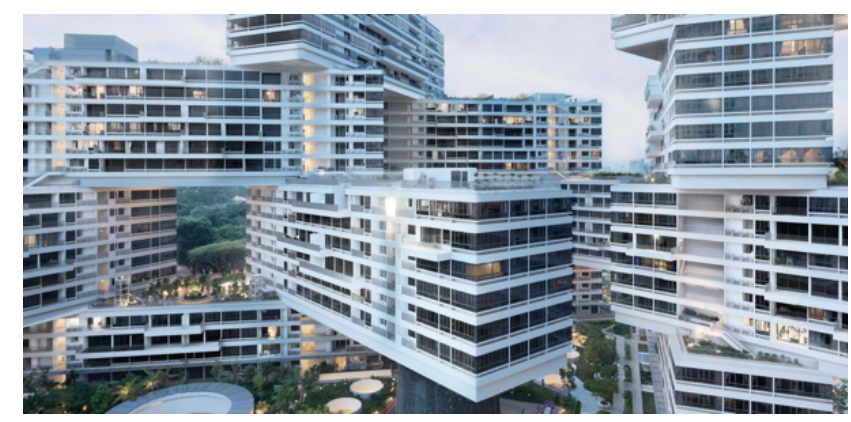

(a)

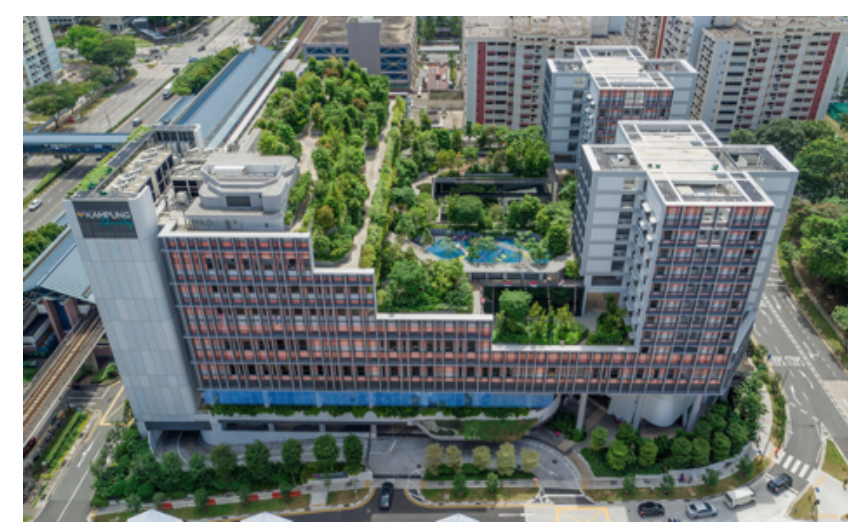

(b)

Figure 4 The (a) interlace and (b) kampung admiralty. Adapted from [45].

Furthermore, in earlier master plans, Singapore was already aiming for it by creating walkable neighborhoods in their new towns. As early as the 1970s, Singapore, being fully aware of its land scarcity, initiated high-density new towns in its peripheral area [46]. The development of these new towns, developed 
from its predecessor of new towns in the UK and US, was based on the neighborhood-unit planning that has been evolving over time from 1928 when it was first coined by Radburn (1928) and Perry (1929). In neighborhood-unit planning, walkability is the central idea of people's movement where a neighborhood must be self-sufficient so that urban facilities can be accessed within walking distance [47]. High density has been the center of housing development in Singapore. It was first planned to provide affordable housing for the citizens, but later, it became the architectural identity for the country.

High-density housing such as The Interlace by Ole Scheeren and Kampung Admiralty by WOHA, a wellestablished Architecture firm based in Singapore, shows that high density does not always have to be related to poverty and slumps. Instead, designs, as shown in Figure 4, can promote more active mobility. Since sustainability became the major concept in urban development in the 1990s, the government upgraded the adopted neighborhood-unit planning to be more accommodative to neighborhood networks by implementing underground paths [48]. Compared to sheltered walkways, underground paths offer more amenities similar to those of shopping malls. It is also safer since people do not have to compete with other transportation and it gives more comprehensive shelter from the weather. Furthermore, in accordance with the new land and transport planning 2040, Singapore conducted a workshop with Jan Gehl through the Center of Livable Cities. The workshop suggested three possible strategies to push forward active mobility: (i) gives the legal basis to active mobility's devices, including personal mobility devices, (ii) providing safe infrastructure for all active mobility vehicles that are separated from other transportation modes, and (iii) planning a comprehensive network of active mobility based on the needs of the users.

\section{20-Minutes Town and 45-Minute City}

While constructing the LTMP 2040, Land Transport Authority (LTA) saw that the number of Singaporeans owning bicycles, e-scooters, and kick scooters was increasing. Whether it is to follow a modern lifestyle or as daily necessities, the data showed that active mobility is starting to be a trend among the citizens. However, infrastructure in many towns was not yet ready to prioritize walking people or people with bicycles. Furthermore, the development of Personal Mobility Devices (PMD) has pushed the government to keep updating its regulations on active mobility. Powerassisted Bicycles, Hoverboard, E-scooter, and Kickboard, are additional personal mobility devices besides bicycles that have gained popularity since 2015 .
It cannot be categorized as either walking or cycling. The users of the PMD often cannot decide on which path or road they should take. After recording more than 130 traffic accidents involving PMD from 2015 to 2017 , LTA published and put into force, Active Mobility Act (AMA) that regulates the space sharing system of the street [49].

Because the development pace of PMD infrastructure cannot keep up with the rise of PMD popularity, accidents still happened even after the enactment of AMA. This has pushed the government to make some amendment in 2020 to the AMA that involves more strict regulation such as mandatory theory test to get a riding permit and a minimum age requirement of 16 for motorized PMDs [50]. The inadequate infrastructure and tough restrictions on PMDs, despite their high popularity, make people feel discouraged to frequently use the active mobility method to travel. Even though the popularity of PMD plays a big part in making cycling and traditional cycling less popular, the aforementioned workshop with Jan Gehl, an urban expert from Finland, assesses the walking and cycling infrastructure of Singapore [42]. Gehl summarized those small details, such as the cycling path design and integration were missing from Singapore's transportation facility. Noticing the importance of fixing the active mobility infrastructure, one of LTMP 2040 's visions is to encourage people to do more walking and cycling by integrating urban development with transport planning and bring back the old neighborhood-unit planning into a more modern context.

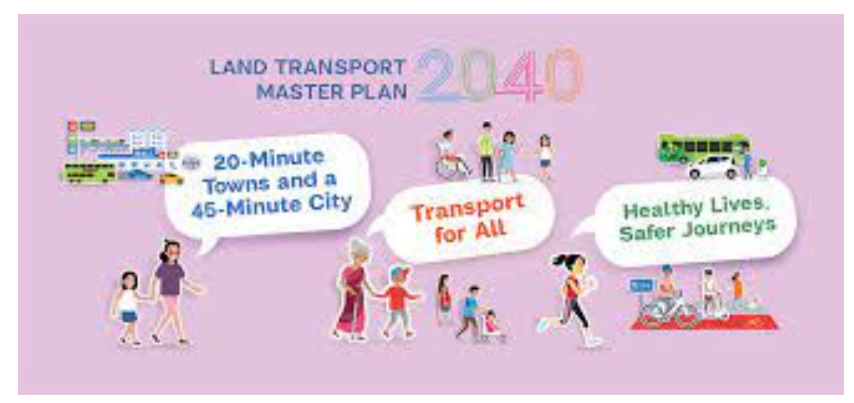

Figure 5 Overview of singapore's land transport master plan (LTMP) 2040. Adapted from [22].

In 2019, Singapore officially released the LTMP 2040 that gained a lot of interest from the public [51], [52]. The master plan has a grand vision of providing a "convenient, well-connected, and fast" transportation system for all. As shown in Figure 5, three main concepts were introduced on how to realize the vision: 20-Minute Towns and 45-Minute City; Transport for All; and Healthy Lives, Safer Journey. Among the three concepts, 20-Minute Towns and 45-Minute City gained 
wider attention nationwide because it was considered ambitious. The concept implies that citizens should be able to reach their nearest neighborhood center within 20 minutes and reach their workplace and business center within 45 minutes by active mobility such as walking, cycling, or riding PMD. It follows similar strategies to walkable cities and the 15-Minute movement started in Paris. Mainly, the goal will be achieved by implementing two strategies, as seen in Figure 6. The first strategy is to bring more urban facilities such as schools, clinics, hawker centers, parks, and retail shops closer to home through a mix-use development. The second strategy is to enhance the walk-cycle-ride option through the enhancement of the infrastructure and policies. Walk and Cycle options consist of active mobility modes such as walking, cycling, and riding PMDs, while the Ride option consists of riding the public transport and using shared transport modes, such as services provided by Grab and Uber. By clearly defining each of the green transportation modes, it made it easier to develop each of them and set measurements to enhance the integration between the modes.

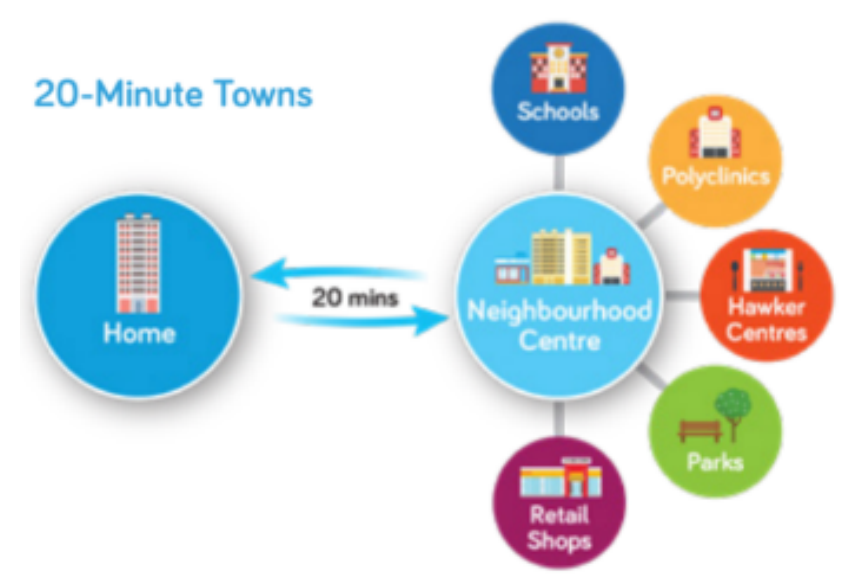

(a)

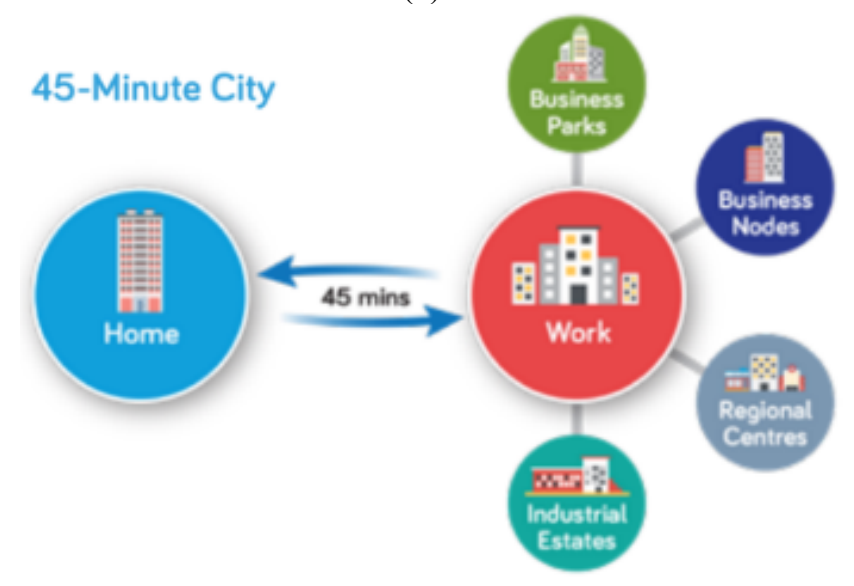

(b)

Figure 6 A diagram explaining the concept of (a) 20-Minute Towns and (b) 45-Minute City. Adapted from [42].
The first infrastructure project planned for the realization of the 20-Minute Towns and 45-Minute City concept is the North-South Corridor (NSC) project that will connect the northernmost part of Singapore to the downtown area located far north [53]. The NSC project is expected to finish in 2026 and has a long history that shows Singapore's effort in achieving green transportation. The project was first published as an expressway for motorized vehicles in 2008. Singapore calls their street that has either a dedicated bus lane or walking and cycling lane as a Transit Priority Corridor and in 2017, NSC was announced to be the first and longest Transit Priority Corridor with $21.5 \mathrm{~km}$ as its length [54]. The main strategy of the project is to connect the disjoint precincts by public transport and active mobility modes. The corridor will lay from Woodlands to Angmo Kio, both are residential areas located in the northern part of Singapore, to Kampong Glam, Bugis, and finally the city center. It will be the first Transit Priority Corridor that has both dedicated bus lanes as well as cycling and PMDs tracks and with this initiative, it will provide a smoother commuting experience as it will shorten the traveling distance for buses up to 30 minutes [54].

Not only shortening the distance in the north-south corridor, but NSC will also be the main collector road for the surrounding areas. As shown in Figure 7, towns such as Yishun and Sembawang will also gain benefit from this project's continuous bus lanes and will reduce travel time up to 15 minutes. This is not a small change based on the fact that many Singaporeans that live in the northern part of the country work in the Central Business District. LTA is very confident that the NSC project will not only enhance the integrity of Singapore's land transport system but also create a greener transportation network. However, as Gehl explained during the workshop, successful streets should be seen not only as a transportation facility but also as a public space where all citizens can participate. Hence, the human aspect of planning and design should not be neglected. The NSC has already been planned as an inclusive corridor where all public and active mobility can take parts of, but it also has to be enjoyable for the people. LTA announced that the design of the cycling and pedestrian tracks will be able to attract people to use the corridor not only for transportation purposes but also for leisure purposes since it will also be connected to the surrounding Park Connectors [55]. 


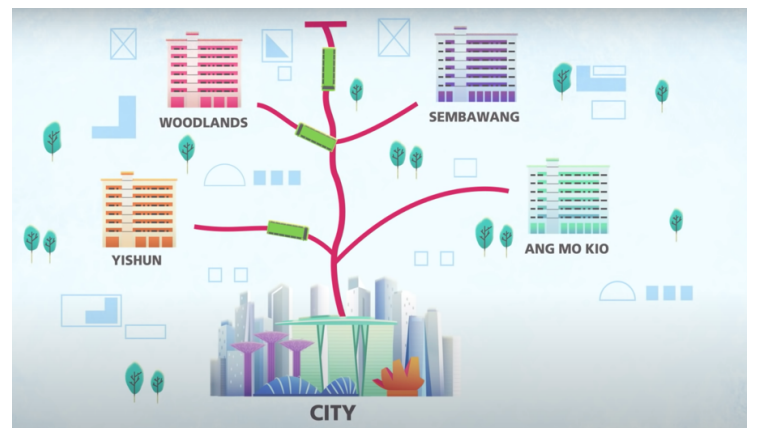

Figure 7 A diagram explaining the concept of the NorthSouth Corridor. Adapted from [42].

\section{$7 \quad$ Perspectives for $15-$ Minute City and Its Application}

The above review of the initiation and development of the 15-Minute City concept as well as how Singapore as the case study, shows what seems to be an ambitious concept turned out to be a feasible plan. 15-Minute City was conceptualized as an effort to bring the city closer to the people in an era of technological advancement where motorized vehicles are everywhere. The 15Minute City concept goes beyond normalizing public transport. It tries to normalize active mobility as a legitimate transportation mode. Learning from Singapore, the 15-Minute City concept is not just about building more urban facilities closer to home. To make it more suitable with the country's socio-geographic character, Singapore modified the concept to be 20Minute Towns and a 45-Minute City. As mentioned in the Land and Transport Master Plan 2040, the planning of the 20-Minute Towns and 45-Minute City involves a multi-level and multi-dimensional process that could take years to fully realize. NSC is the only one of Singapore's concrete implementations of the concept so far was planned to take almost ten years to complete.

The case of Singapore shows that it is more than the reconstruction of urban structure. It involves changing mindset and introducing a new lifestyle to the people. Having had major social and economic development during the ' $60 \mathrm{~s}$, Singapore transformed from a thirdworld country into a world-class city-state. One effect of Singapore's rapid and complete urban transformation is the overly planned and rigid land-use zoning. The land use includes Business District on the center; residential areas in the periphery; industrial and port areas on the westernmost part; and MEC (meeting, exhibition, and convention) facilities, as well as the airport located on the easternmost part of the island. Even though each town was designed carefully to include basic amenities, the distance between several core facilities (especially the workplaces) is still quite long, encouraging people to prefer their private cars over public transport and active mobility. Therefore, the
NSC is such a breakthrough strategy to achieve more connectivity nationwide, making the 45-Minute City goal to be feasible. In the future, de-clustering its highly centralized land use would be Singapore's biggest challenge in fully realizing the LTMP 2040. However, the initial projects such as the NSC shows that Singapore's plan for a future sustainable transportation system to be feasible.

\section{References}

[1] K. Hourihan, "Urban planning in the twentieth century," Urban History, vol. 27, no. 3, pp. 384-396, 2000.

[2] E. Witoelar, "People centred cities in a globalizing world: Issues in governance," Transp. Commun. Bull. Asia Pac, vol. 71, pp. 18, 2001.

[3] C. Moreno, Z. Allam, D. Chabaud, C. Gall, and F. Pratlong, "Introducing the "15-Minute City': Sustainability, resilience and place identity in future post-pandemic cities," Smart Cities, vol. 4, no. 1, pp. 93-111, 2021.

[4] G. Pozoukidou and Z. Chatziyiannaki, "15-Minute City: Decomposing the New Urban Planning Eutopia," Sustainability, vol. 13, no. 2, p. 928, 2021.

[5] J. R. Brown, E. A. Morris, and B. D. Taylor, "Planning for cars in cities: Planners, engineers, and freeways in the 20th century," $J$. Am. Plan. Assoc., vol. 75, no. 2, pp. 161-177, 2009.

[6] A. de Barcelona, "Urban mobility plan of Barcelona. PMU 2013 2018," http://mobilitat. ajuntament. barcelona. cat/sites/default/files/docs/PMU\% 20BCN, 2014.

[7] C. Vitrano, "COVID-19 and Public Transport," 2021.

[8] L. Liu, H. J. Miller, and J. Scheff, "The impacts of COVID-19 pandemic on public transit demand in the United States," PLoS One, vol. 15, no. 11, p. e0242476, 2020.

[9] Z. Allam and D. S. Jones, "Pandemic stricken cities on lockdown. Where are our planning and design professionals [now, then and into the future]?," Land use policy, vol. 97, p. 104805, 2020.

[10] K. Willsher, "Paris mayor unveils' 15-minute city'plan in reelection campaign," Guard., vol. 7, 2020.

[11] M. Weng et al., "The 15-minute walkable neighborhoods: Measurement, social inequalities and implications for building healthy communities in urban China," J. Transp. Heal., vol. 13, pp. 259-273, 2019.

[12] M. Carmona, "Place value: Place quality and its impact on health, social, economic and environmental outcomes," J. urban Des., vol. 24, no. 1, pp. 1-48, 2019.

[13] P. Yeung, "How '15-Minute Cities' Will Change the Way We Socialise," $\quad B B C$. https//www. com/worklife/article/20201214-how-15-minute-cities-willchange-theway-we-socialise (accessed 2021), 2021.

[14] Z. Taylor and J. Van Nostrand, "Shaping the Toronto Region," Past, Present. Futur. An Explor. Potential Eff. to Plan. Policies Gov. Greenf. Dev. Gt. Golden Horseshoe, 2008.

[15] C. W. Hackett, An Analysis of Planned Industrial Districts, no. 4. Bureau of Business Research, College of Business Administration, University ..., 1956.

[16] P. Williams, B. Pocock, and K. Bridge, "Linked up lives: Putting together work, home and community in ten Australian suburbs," Overv. Report. Adelaide Cent. Work. Life. Univ. South Aust., 2009.

[17] N. Dempsey, C. Brown, and G. Bramley, "The key to sustainable urban development in UK cities? The influence of density on social sustainability," Prog. Plann., vol. 77, no. 3, pp. 89-141, 2012.

[18] K. Brookfield, "Residents' preferences for walkable neighbourhoods," J. urban Des., vol. 22, no. 1, pp. 44-58, 2017.

[19] T. Wong, "Singapore: What's it like in the best place to live during Covid?," 2021. [Online]. Available: https://www.bbc.com/news/world-asia-56939261. [Accessed: 25July-2021].

[20] S. Wray, "Singapore, Seoul and London ranked top for smart city 
governance," 2021. [Online]. Available: https://citiestoday.com/singapore-seoul-and-london-ranked-top-for-smartcity-governance/. [Accessed: 25-July-2021].

[21] N. J. Sen, "Singapore rises 2 spots to 11 th in ranking of world's best cities, boosted by mass transit system, port," 2021. [Online]. Available: https://www.todayonline.com/singapore/singaporerises-two-spots-11 th-ranking-worlds-best-cities-boosted-masstransit-system-port. [Accessed: 25-July-2021].

[22] Land Transport Authority, "Trends observed from Household Interview Travel Survey (HITS) 2016," 2018. [Online]. Available: https://www.lta.gov.sg/data/ apps/news/press/2018/20180919_LTMP2040_Public_consultati on doc AnnexA.pdf. [Accessed: 21-Nov-2021].

[23] R. Dhaliwal and M. Lim, "All aboard for the subway age," The Straits Times, p. 1, 1987.

[24] S. Shamsuddin, N. R. A. Hassan, and S. F. I. Bilyamin, "Walkable environment in increasing the liveability of a city," ProcediaSocial Behav. Sci., vol. 50, pp. 167-178, 2012.

[25] M. How, "New system map shows MRT lines once entirely in effect by 2030, NTU to get MRT stations in 2028," 2019. [Online]. Available: https://mothership.sg/2019/04/new-mrtlines-map-singapore/. [Accessed: 25-July-2021].

[26] M. Rahman and H. C. Chin, "Sustainable urban transport in Singapore: a Balanced Scorecard," OIDA Int. J. Sustain. Dev., vol. 2, no. 10, pp. 19-42, 2011.

[27] M. de Percy and J. Wanna, Road Pricing and Provision: Changed Traffic Conditions Ahead. ANU Press, 2018.

[28] D. Moser, "Singapore: The 45 Minute City," 2020. [Online]. Available: https://www.transformativemobility.org/news/singapore. [Accessed: 26-July-2021].

[29] L. Schipper, M. Cordeiro, and W.-S. Ng, "Measuring the carbon dioxide impacts of urban transport projects in developing countries," 2007.

[30] I. Kutani, "Study on Energy Efficiency Improvement in the Transport Sector Through Transport Improvement and Smart Community Development in the Urban Area," 2013. [Online]. Available: https://www.eria.org/RPR-FY2012-29.pdf. [Accessed: 21-Nov-2021].

[31] T. T. Wei, "COE prices close higher across all five categories," 2021. [Online]. Available: https://www.straitstimes.com/singapore/transport/coe-pricesclose-higher-across-all-five-categories. [Accessed: 5-Aug-2021].

[32] W. K. Yi, "3 stations on Thomson-East Coast Line begin operations," $2020 . \quad$ [Online]. Available: https://www.straitstimes.com/singapore/transport/3-stations-onthomson-east-coast-line-begin-operations. [Accessed: 5-Aug2021].

[33] C. Chen, D. Varley, and J. Chen, "What affects transit ridership? A dynamic analysis involving multiple factors, lags and asymmetric behaviour," Urban Stud., vol. 48, no. 9, pp. 18931908,2011

[34] A. Chan, "How Much Does It Truly Cost To Maintain A Car In Singapore?," 2021. [Online]. Available: https://www.singsaver.com.sg/blog/car-maintenance-cost-insingapore. [Accessed: 6-Aug-2021].

[35] S. H. Lam and T. D. Toan, "Land transport policy and public transport in Singapore," Transportation (Amst)., vol. 33, no. 2, pp. 171-188, 2006.

[36] P. Sayeg, "First Class: Singapore's I-Transport: a World Class Transport System in the Making," Traffic Technol. Int., 2001.

[37] K. Wong, "Environmentally sustainable transport-Singapore's experience'," in Fourth Regional EST Forum, 2009, pp. 24-26.

[38] L. X. Yuan, J. New Yuxin, S. Z. Yan, and T. G. Jing, "Are MRT Train Seats Comfortable? Are They as Comfortable as Those on Buses?," $2015 . \quad$ [Online]. Available: https://transportaeto.weebly.com/discussion-13.html. [Accessed: 8-Aug-2021].

[39] Railway Pro, "Singapore to trial McLaren technology on MRT trains," $2018 . \quad$ [Online]. Available: https://www.railwaypro.com/wp/singapore-to-trial-mclaren- technology-on-mrt-trains/. [Accessed: 8-Aug-2021].

[40] M. C. R. López and Y. D. Wong, "Attitudes towards active mobility in Singapore: a qualitative study," Case Stud. Transp. policy, vol. 5, no. 4, pp. 662-670, 2017.

[41] A. Z. Abdullah, "Plan to expand bicycle paths welcomed, but more needed to encourage Singapore's cycling vision," 2020. [Online].

Available: https://www.channelnewsasia.com/singapore/plan-expandbicycle-paths-welcomed-more-needed-encourage-singaporescycling-vision-771201. [Accessed: 9-Aug-2021].

[42] C. Ho, "Missing Link in Singapore's Land Transport Planning: A Comprehensive Active Mobility Network Plan," 2020. [Online]. Available: https://www.clc.gov.sg/docs/defaultsource/commentaries/bc-2020-01-missing-link-in-singaporestransport.pdf. [Accessed: 1-Nov-2021].

[43] I. Avila-Palencia et al., "Active mobility and subjective general health: Roles of mental health, social support and physical activity," J. Transp. Heal., vol. 5, p. S76, 2017.

[44] C. Koszowski, R. Gerike, S. Hubrich, T. Götschi, M. Pohle, and R. Wittwer, "Active mobility: bringing together transport planning, urban planning, and public health," in Towards UserCentric Transport in Europe, Springer, 2019, pp. 149-171.

[45] O. Shen, "Design for Improving Social Interaction of High-rise Housing Community." Universiti Teknologi Malaysia, 2017.

[46] I. S. Cho and B. Križnik, Community-based urban development: Evolving urban paradigms in Singapore and Seoul. Springer, 2016.

[47] A. Alexander, Britain's New Towns: Garden cities to sustainable communities. Routledge, 2009.

[48] J. Lee and S. Park, "Exploring neighborhood unit's planning elements and configuration methods in Seoul and Singapore from a walkability perspective," Sustainability, vol. 10, no. 4, p. 988 , 2018

[49] K. Wong, "Regulations for cyclists, PMD users 'strictly enforced' via patrols at hot spots: LTA," 2019. [Online]. Available: https://www.todayonline.com/voices/regulations-cyclists-pmdusers-strictly-enforced-patrols-hot-spots-lta. [Accessed: 12-Aug2021].

[50] D. Tan, "Active Mobility (Amendment) Bill \& Shared Mobility Enterprises (Control and Licensing) Bill," 2020. [Online]. Available: https://www2.wp.sg/active-mobility-amendment-billand-shared-mobility-enterprises-control-and-licensing-billspeech-by-dennis-tan/. [Accessed: 2-Nov-2021].

[51] G. Teo, "'45-minute city, 20-minute towns': Advisory panel outlines vision for Land Transport Master Plan 2040," 2019. [Online].

Available: https:/www.channelnewsasia.com/singapore/45-minute-city-20minute-towns-land-transport-master-plan-2040-906091. [Accessed: 12-Aug-2021].

[52] Intelligent Transport, "Singapore's LTA announces 2040 transport Master Plan," 2019. [Online]. Available: https://www.intelligenttransport.com/transportnews/81321/singapore-lta-2040-master-plan/. [Accessed: 12Aug-2021].

[53] A. Lim, "North-South integrated transport corridor expected to be completed around 2026: LTA," 2016. [Online]. Available: https://www.straitstimes.com/singapore/transport/north-southintegrated-transport-corridor-expected-to-be-completed-around2026. [Accessed: 12-Aug-2021].

[54] Urban Redevelopment Authority, "Better Connectivity for All," 2021. [Online]. Available: https://www.ura.gov.sg/Corporate/Planning/MasterPlan/Themes/Convenient-and-Sustainable-Mobility/BetterConnectivity-for-All. [Accessed: 12-Aug-2021].

[55] F. Ismailzade, "The 'North-South' transport corridor finally kicks off," $2016 . \quad$ [Online]. Available: https://www.cacianalyst.org/publications/analyticalarticles/item/13395-the-"north-south"-transport-corridor-finallykicks-off.html. [Accessed: 21-Nov-2021]. 